\title{
Analisis Faktor-Faktor yang mempengaruhi Kinerja Keuangan (Studi Kasus Pada Bank Umum Syariah yang terdaftar di Otoritas Jasa Keuangan Periode 2015-2019)
}

\author{
Indah Marlina \\ e-mail: indahmrlna@gmail.com \\ Suhono \\ e-mail: suhono@fe.unsika.ac.id \\ (Program Studi Akuntansi, Fakultas Ekonomi, Universitas Singaperbangsa, Karawang)
}

\begin{abstract}
ABSTRAK : Penelitian ini bertujuan untuk mengetahui faktor-faktor apa saja yang dapat mempengaruhi kinerja kauangan. Populasi dalam penelitian sebanyak 14 dengan Sampel dalam penelitian ini sebanyak 7 Bank Umum Syariah. Teknik pengambilan sampel yaitu purposive sampling. Hasil penelitian menyatakan bahwa CAR tidak berpengaruh terhadap ROA. FDR berpengaruh terhadap ROA dan BOPO berpengaruh negatif terhadap ROA. Pengolahan data menggunakan SPSS V.21
\end{abstract}

Kata kunci: $C A R, F D R, B O P O$ dan $R O A$

ABSTRACT : This study aims to determine the factors that can affect accounting performance. The population in the study was 14 with the sample in this study were 7 Islamic Commercial Banks. The sampling technique was purposive sampling. The results of the study stated that CAR had no effect on ROA. FDR has a negative effect on ROA and BOPO has a negative effect on ROA. Data processing using SPSS V.21

Keywords: $C A R, F D R, B O P O$ dan ROA 


\section{PENDAHULUAN}

Semua yang diatur dalam sebuah kehidupan manusia yang ada di Al Qur'an termasuk bidang perekonomian, aktivitas sosial, investasi hal tersebut tidak lepas dari syariat islam. Kegiatan ekonomi yang di perbolehkan dalam islam yaitu kegiatan yang didasarkan prinsip saling meridhoi supaya hal yang tak diinginkan sperti kemudharatan tidak terjadi. Kegiatan ekonomi dalam islam tidak diperbolehkan adanya riba, gharar, dan transaksi yang bisa membuat salah satu pihak mengalami kerugian, hal ini sesuai dalam QS Al Baqarah:275. Yang memiliki arti bahwa Allah SWT mengharamkan riba dan menghalalkan jual beli (Wahyuni 2016).

Pada saat ini perkembangan perekonomian di Indonesia tak terlepas dari peran perbankan yang mampu mendorong perekonomian di Indonesia semakin maju. Dalam proses keegiatan yang dilakukan oleh bank pasti membutuhkan dana, oleh sebab itu bank harus mampu menghimpun dana darimanapun. Apabila bank memiliki dana yang cukup maka akan baik pula kontribusi perbankan dalam melaksanakan kegiatannya. Selain itu, bank juga memiliki peran dalam proses pembangunan nasional untuk meningkatkan ekonomi serta dalam hal stabilitas nasional, akan mampu menghasilkan pemerataan pembangunan, serta mampu meningkatkan kemakmuran masyarakat (Hamdani et al. 2018)

Perkembangan bank umum syariah di Indonesia berjalan dengan baik salah satunya yaitu Bank Umum Syariah yang memiliki perkembangan positif dari tahun 2015-2019. Hal ini bisa terlihat dari total asset pada bank umum syariah.

Tabel 1

Perkembangan Asset Bank Umum Syariah (Dalam Milyar Rupiah)

\begin{tabular}{|c|r|}
\hline \multicolumn{1}{|l|}{ Tahun } & Total Aset \\
\hline 2015 & 213.423 \\
\hline 2016 & 254.184 \\
\hline 2017 & 288.027 \\
\hline 2018 & 316.691 \\
\hline 2019 & 350.364 \\
\hline
\end{tabular}

Sumber: Otoritas Jasa Keuangan,2021

Dari tabel 1 bahwa perkembangan bank umum syariah memiliki perkembangan yang baik walaupun tidak memiliki perkembangan yang cukup pesat. Dengan demikian bank umum syariah memiliki pertumbuhan ekonomi yang baik.

Bank umum syariah mempunyai peranan yang penting dalam progres perkembangan perekonomian di Indonesia. Oleh sebab itu, kinerja keuangan bank umum syariah seharusnya dilaksanakan dengan maksimal agar nasabah atau pihak yang menamkan modalnya menerima profit yang baik. Sehingga nasabah atau pihak yang menanamkan modalnya tetap konsisten menanamkan modalnya dan tak berpindah kepada bank lain. (Hamdani et al. 2018) menyatakan bahwa pada saat ini pertumbuhan Bank Umum Syariah dapat meningkat, hal ini tidak terlepas dari upaya ataupun minat masyarakat mempercayai jasa perbankan syariah, terutama bagi nasabah yang mengharapkan keuntungannya kembali.

Kinerja bank umum syariah mesti terus ditingkatkan sebab merupakan hal yang benar-benar penting bagi perusahaan. Profitabilitas adalah alat ukur yang bisa dipakai oleh bank untuk memberikan kepercayaan kepada masyarakat bahwa kinerja bank tersebut baik. Maka dari itu tingkat profitabilitas bank mesti dijaga dengan maksimal. (Dendawijaya 2005) menyatakan bahwa ROA pada Bank besar maka tingkat keuntungan yang di dapatkan oleh akan besar pula. Dengan 
demikian apabila suatu Bank memiliki tingkat ROA yang besar maka nasabah akan menilai bahwa Bank tersebut memiliki kinerja yang baik.

Pengukuran kinerja keuanga bisa dengan cara menganalisa rasio keuangan pada bank tersebut. Rasio profitabilitas, likuiditas dan solvabilitias merupakan rasio keuangan yang digunakan dalam penelitian ini. Menurut Fahmi 2014 dalam (Mujtahidah and Laily 2016) mengemukakan bahwa untuk menilai efektivitas dalam mendapatkan laba perusahaan baik yang dihasilkan dari penjualan Maupun investasi dapat diukur dengan rasio profitabilitas. Dengan demikian, rasio profitabilitas mampu memperlihatkan mengenai kesanggupan perusahaan dalam mendapatkan profit dengan cara memanfaatkan sumber daya perusahaan baik dari aktivitas operasional dan penjualan. Return On Asset (ROA dipakai dalam penelitian ini untuk mengukur rasio profitabilitas.

Rasio solvabilitas merupakan rasio yang digunakan perusahaan dalam mengukur kemampuan suatu perusahaan memenuhi kewajiban jangka panjangnya. (Hanafi and Halim 2012). Rasio solvabilitas ini digunakan untuk menilai seberapa besar perusahaan dibiyai dengan hutang. Rasio solvabilitas dalam penelitian ini yaitu Capital Adequacy Ratio (CAR).

Rasio likuiditas merupakan rasio untuk menilai likuiditas dalam jangka waktu yang pendek. Perusahaan dengan memperlihatkan besarnya aktiva lancar relatif terhadap hutang lancarnya. Rasio lancar untuk menilai kesanggupan perusahaan dalam melunasi utang dalam jangka pendeknya memakai aktiva lancarnya (Hanafi and Halim 2012). Rasio FDR dalam penelitian ini dijadikan sebagai Rasio Likuiditas.

Selain rasio di atas rasio Pendapatan Operasional (BOPO) dapat dijadikan sebagai rasio yang dapat meningkatkan pendapatan dan menekan biaya. rasio BOPO adalah rasio ntuk menilai ingkat efisiensi dan kesanggupan bank dalam melaksanakan aktivitas operasinya. Bank yang efisien dalam menekan tarif operasionalnya bisa mengurangi kerugian akibat ketidak efisienan bank dalam mengelola usahanya sehingga laba yang didapatkan juga akan meningkat (Dendawijaya 2009). Berikut adalah perkembangan Return On Asset (ROA) Pada Bank Umum Syariah Periode 2015-2019.

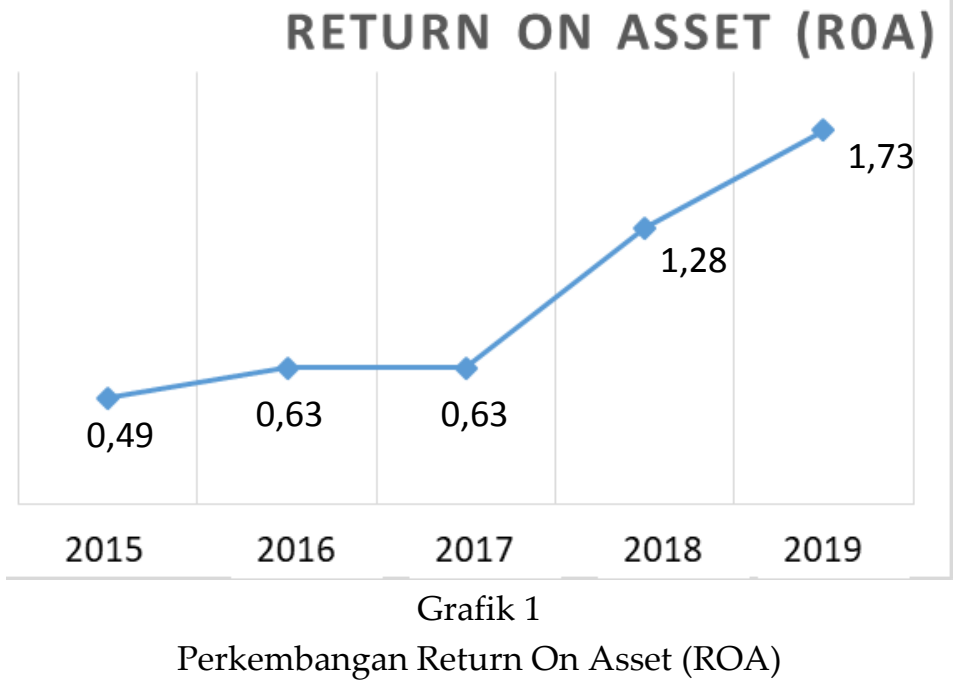

Berdasarkan grafik 1 mengenai rasio Return On Asset (ROA) pada tahun 2015-2019 mengalami perubahan yang fluktuatif. Tahun 2015 ROA sebesar 0,49\%. Tahun 206-2017 sebesar 0,65\% artinya dalam 2 tahun bank tidak mengalami peningkatan ROA. Pada tahun 2018 sebsar 1,2\% dan pada tahun 2019 sebesar 1,73\%. Menurut (Hamdani et al. 2018) menyatakan bahwa ketika ROA terus 
naik maka akan menghasilkan profitabilitas yang baik karena perusahaan akan memperoleh profit yang besar. Meningkatnya ROA dapat dipengaruhi oleh rasio keuangan lainnya, seperti pada grafik di bawah ini mengenai perkembangan CAR pada Bank Umum Syariah periode 2015-2019.

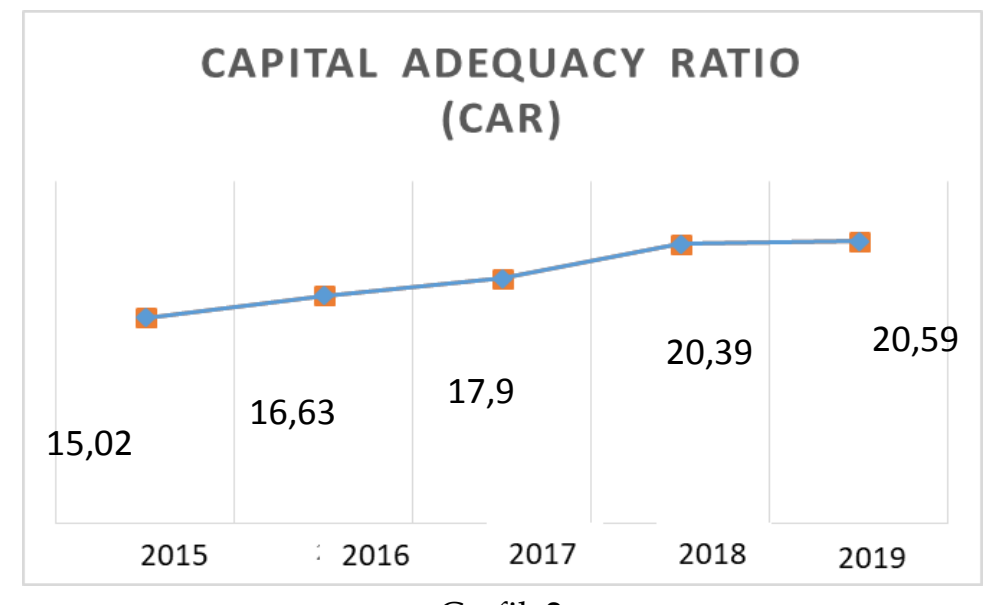

Grafik 2

Perkembangan Capital Adequacy Ratio (CAR)

Rasio CAR pada tahun 2015-2019 terus mengalami kenaikan. Artinya CAR yang dimiliki Bank Umum Syariah memiliki kategori yang baik, hal ini diperkuat dengan adanya peraturan BI No.15/12/PBI/2013 tentang kewajiban penyediaan modal minimum Bank Umum yang menyatakan bahwa Bank harus memiliki modal minimum sebesar $6 \%$. Tetapi permasalahannya dalam grafik 2 pada tahun 2017 menunjuukan bahwa CAR tidak berbanding lurus dengan ROA dimana CAR mengalami kenaikan tetapi ROA tetap stabil. Selain CAR fakor yang dapat mempengaruhi kinerja keuangan ialah FDR. Berikut adalah perkembangan FDR selama periode 2015-2019 di Bank Umum Syariah.

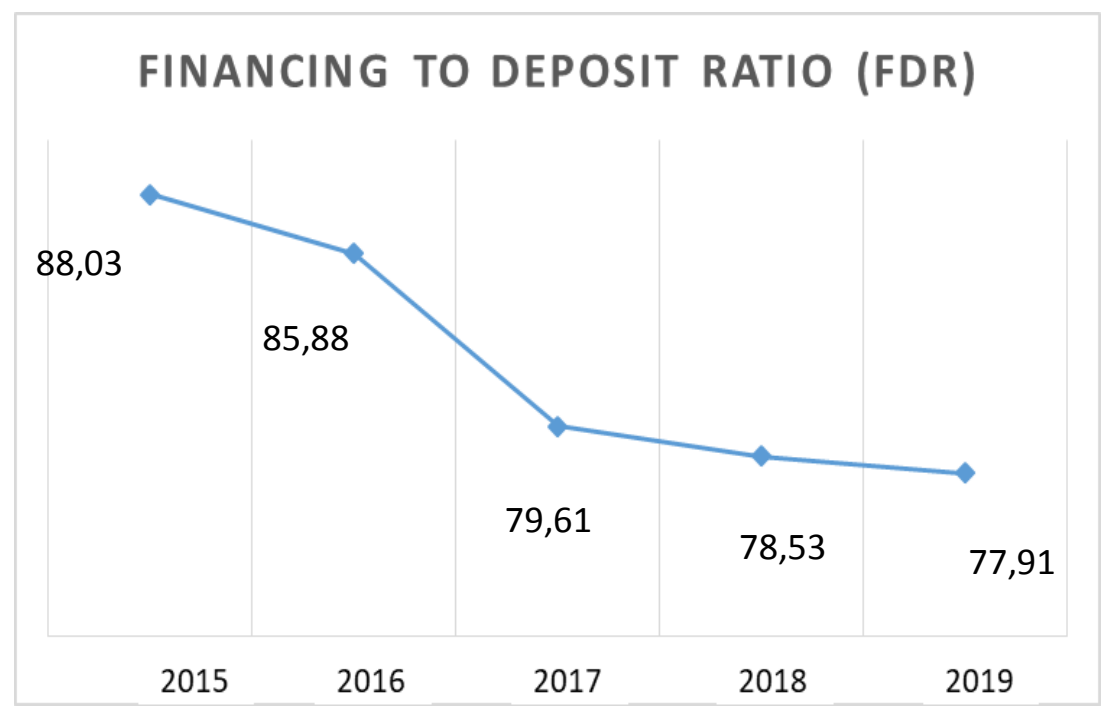

Grafik 3

Perkembangan Financing To Deposit Ratio (FDR)

Rasio FDR pada tahun 2015-2019 terus mengalami penurunan. Turunnya FDR ini tidak sejalan dengan naiknya ROA. Seharusnya ketika FDR mengalami penurunan ROA pun akan 
mengalami penurunan. Permasalahan yang terjadi ini dimana FDR mengalami penurunan tetapi ROA mengalami peningkatan. Selain CAR dan FDR yang dapat menjadi faktor yang mempengaruhi ROA yaitu rasio BOPO. Berikut perkembangan BOPO pada Bank Umum Syariah periode 2015-2019.

\section{PENDAPATAN OPERASIONAL (BOPO)}

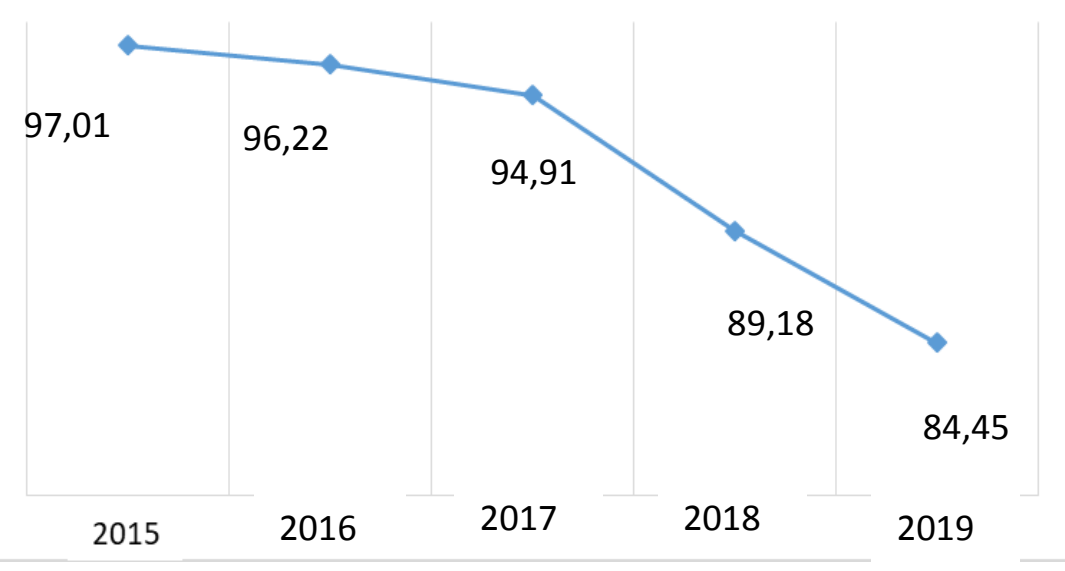

Grafik 4

Perkembangan Pendapatan Operasional (BOPO)

Rasio BOPO dari tahun 2015-2019 terus mengalami penurunan hal ini menunjukkan keadaan yang baik pada bank. Akan tetapi, jika BOPO melewati batas maksimum yang sudah ditetapkan oleh Bank Indonesia yaitu 90\% maka kinerja keuangan tidak sehat. Pada grafik 3 nilai BOPO lebih dari 90\% pada tahun 2015-2017 artinya kinerja keuangan tidak sehat.

Menurut (Simatupang and Franzlay 2016) dalam penelitiannya menghasilkan bahwa CAR berpengaruh signifikan terhadap ROA. (Sudarsono 2017) menyatakan bahwa CAR memiliki memiliki pengaruh negatif terhadap ROA. Sedangkan menurut (Munir 2018) menyatakan bahwa CAR tidak memiliki pengaruh terhadap ROA. Menurut (Marisya 2019) bahwa FDR memiliki pengaruh yang positif dan signifikan terhadap ROA. Sedangkan menurut (Munir 2018) menyatakan mengenai FDR tidak memiliki pengaruh terhadap ROA. Menurut (Ali and Laksono 2017) menyatakan bahwa BOPO memiliki pengaruh terhadap ROA. Dalam penelitian (Sudarsono and Supriani 2018) menghasilkan bahwa BOPO memiliki pengaruh yang positif terhadap ROA. (Suwandi and Oetomo 2017) menyatakan mengenai BOPO memiliki pengaruh yang negative terhadap ROA.

Berdasarkan permasalahan beserta adanya reaserch gap sehingga adanya temuan yang berbeda mengenai faktor-faktor yang mempengaruhi Return On Asset (ROA). Dengan adanya permasalahan di atas maka tujuan dilakukannya penelitian ini adalah untuk mengetahui faktorfaktor yang mempengaruhi kinerja keuangan di Bank Umum Syariah Periode 2015-2019.

\section{TINJAUAN PUSTAKA}

\section{Kinerja Keuangan}

Menurut Fahmi (Fahmi 2014) "kinerja keuangan ialah suatu analisis yang dilakukan untuk melihat keberhasilan perusahaan dalam pengelolaaan organisasi tersebut bisa dicapai secara keseluruhan atau tidak yang bisa disesuaikan pada aturan-aturan pelaksanaan keuangan secara baik dan benar". Berdasarkan hal tersebut dapat disimpulkan bahwa kinerja keuangan ialah peneliaian mengenai seberapa baik tujuan perekonomian yang bisa perusahaan capai, karena tercapainya tujuan perekonomian berarti masyarakat akan sejahtera secara maksimal. 


\section{Rasio Keuangan}

Rasio keuangan ialah rasio yang menerangkan mengenai sebuah keadaan keuangan dengan mencari hubungan mengenai pos-pos yang terdapat di laporan keuangan perusahaan (Prastowo 2015). Penerapan rasio keuangan akan mampu menerangkan serta memberikan ilustrasi perihal baik dan buruknya suatu kondisi keuangan yang dimiliki perusahaan, dengan memperbandingkan rasio pada saat ini dengan rasio yang akan datang (Fahmi 2014).

\section{Capital Aduacy Ratio (CAR)}

Menurut (Dendawijaya 2009) CAR ialah rasio yang dapat dipakai oleh bank untuk mengukur kinerja dalam menilai modal yang cukup yang dimiliki oleh bank sebagai pendukung aktiva yang menjadikan risiko pada bank, contohnya yaitu kredit yang diberikan. Rasio CAR yang seharusnya dimiliki oleh bank minimal 15\% hal ini telah ditentukan oleh Bank Indonesia.

\section{Financing To Deposit Ratio (FDR)}

FDR adalah rasio yang dipakai oleh bank untuk menilai tingkat likuiditas, dengan metode memperbandingkan antara pembiayaan yang disalurkan oleh bank dengan total dana yang dihimpun dari nasabah sehingga bank bisa mengetahui kesanggupan bank dalam membayar kewajibannya dalam jangka waktu yang pendek. Tingkat profit bank dapat ditentukan oleh besarnya total pembiayaan yang disalurkan. Kerugian terjadi ketika dana yang terhimpun berjumlah besat tapi bank tak sanggup memberikan pembiayaan dengan optimal (Widantika and others 2017).

\section{Pendapatan Operasional (BOPO)}

BOPO ialah rasio yang dapat dipakai oleh bank untuk dengan tujuan memperbandingkan antara tarif operasional dengan pendapatan operasional, semakin kecil BOPO maka semakin baik kinerja yang dilakukan oleh bank, sebab lebih efisien dalam menerapkan sumber daya yang ada di perusahaan. Besarnya rasio BOPO yang yang harus dimiliki oleh bank yakni sebesar 93,52\%, hal ini sejajar dengan ketetapan yang dikeluarkan oleh Bank Indonesia (Syakhrun, Amin, and Anwar 2019).

\section{Return On Asset (ROA)}

ROA merupakan rasio yang diterapkan oleh bank untuk mengamati sejauh mana investasi yang sudah ditanamkan sanggup memberikan pengembalian profit yang layak dengan yang diinginkan. ROA yang bernilai positif mampu memperlihatkan bahwa total aktiva yang dipergunakan untuk beroperasi, perusahaan sanggup memberikan laba bagi perusahaan. Sebaliknya jika ROA benilai negatif memperlihatkan bahwa perusahaan akan mengalami kerugian (Fahmi 2015).

\section{METODE}

Jenis penelitian yang digunakan adalah kuantitatif deskriptif yaitu untuk mengetahui keberadaan variabel mandiri, baik hanya pada satu variabel atau lebih (variabel yang berdiri sendiri atau variabel bebas) tanpa membuat perbandingan variabel itu sendiri dan mencari hubungan dengan variabel lain (Sugiyono 2017). Metode analisis adalah regresi linear berganda. Populasi dalam penelitian ini yaitu seluruh Bank Umum yang terdaftar di OJK sebanyak 14 Bank dan sampel penelitian sebanyak 7 Bank dengan teknik pengambilan sampel adalah purposive sampling. Teknik pengumpulan data dalam penelitian ini adalah Penelitian kepustakaan merupakan teknik pengumpulan data dari beberapa buku da literature tentang perbankan yang berkaitan dengan permasalahan dalam penelitian. Alat analisis menggunakan SPPS v.21 


\section{PEMBAHASAN}

Analisis Regresi Linear Berganda

Tabel 2

Hasil Analisis Regresi Berganda

Coefficients $^{\mathrm{a}}$

\begin{tabular}{|c|c|c|c|c|c|c|}
\hline \multirow[t]{2}{*}{ Mode } & & \multicolumn{2}{|c|}{ Unstandardized Coefficients } & \multirow{2}{*}{$\begin{array}{c}\begin{array}{c}\text { Standardized } \\
\text { Coefficients }\end{array} \\
\text { Beta }\end{array}$} & \multirow[t]{2}{*}{$\mathrm{t}$} & \multirow[t]{2}{*}{ Sig. } \\
\hline & & B & Std. Error & & & \\
\hline \multirow{4}{*}{1} & (Constant) & ,342 & ,242 & & 1,411 &, 169 \\
\hline & CAR &, 021 & ,038 &, 070 &, 549 &, 587 \\
\hline & FDR &, 113 & 034 & ,378 & 3,281 &, 003 \\
\hline & BOPO &,- 261 & 044 &,- 794 & $-5,930$ &, 000 \\
\hline
\end{tabular}

a. Dependent Variable: ROA

Sumber: Data diolah peneliti,2021

Berdasarkan tabel 2 menunjukkan bahwa nilai konstanta sebesar 0,342. Koefisien regresi CAR yaitu 0,021, koefisien regresi FDR yaitu 0,113 dan koefisien regresi BOPO yaitu -0,261. Dari hasil tersebut, maka peneliti memberikan gambaran mengenai regresi persamaan adalah sebagai berikut:

$$
\mathrm{Y}=0,342+(0,021) \mathrm{X}_{1}+(0,113) \mathrm{X}_{2}+(-0,261) \mathrm{X}_{3}
$$

Berdasarkan persamaan diatas maka dapat diketahui bahwa:

1. Nilai koefisien regresi CAR sebesar 0,021 artinya jika CAR mengalami kenaikan satu poin maka ROA akan turun sebesar 0,021 atau sebaliknya jika CAR turun satu poin maka ROA akan naik sebesar 0,021

2. Nilai koefisien regresi FDR sebesar 0,113 artinya jika FDR mengalami kenaikan satu poin maka ROA akan turun sebesar 0,113 atau sebaliknya jika FDR turun satu poin maka ROA akan naik sebesar 0,113

3. Nilai koefisien regresi BOPO sebesar $-0,261$ artinya jika BOPO mengalami kenaikan satu poin maka ROA akan turun sebesar 0,261 atau sebaliknya jika CAR turun satu poin maka ROA akan naik sebesar 0,261.

\section{Uji T}

Uji $\mathrm{t}$ dalam penelitian ini bertujuan untuk mengetahui atau menguji seberapa jauh satu variabel indipenden mempengaruhi secara individual dalam menerangkan variasi variabel dependen. Berikut adalah hasil uji t dalam penelitian

Tabel 3

\section{Hasil Uji t}

Coefficients $^{a}$

\begin{tabular}{|c|c|c|c|c|c|c|}
\hline \multirow[t]{2}{*}{ Model } & & \multicolumn{2}{|c|}{ Unstandardized Coefficients } & \multirow{2}{*}{$\begin{array}{c}\begin{array}{c}\text { Standardized } \\
\text { Coefficients }\end{array} \\
\text { Beta } \\
\end{array}$} & \multirow[t]{2}{*}{$\mathrm{t}$} & \multirow[t]{2}{*}{ Sig. } \\
\hline & & B & Std. Error & & & \\
\hline \multirow{3}{*}{1} & (Constant) & ,342 & ,242 & & 1,411 & , 169 \\
\hline & CAR & 021 & ,038 &, 070 &, 549 &, 587 \\
\hline & FDR &, 113 & ,034 & ,378 & 3,281 & ,003 \\
\hline
\end{tabular}




\begin{tabular}{llllll} 
BOPO &,- 261 &, 044 &,- 794 & $-5,930$ &, 000 \\
\hline
\end{tabular}

a. Dependent Variable: ROA

Sumber: Data diolah peneliti,2021

Berdasarkan tabel 3 hasil uji t yang bertujuan untuk menguji pengaruh masing-masing variabel indipenden terhadap variabel dependen. Pengujian ini menggunakan uji dua sisi dan tingkat signifikan sebesar 0,05 .

Pada avariabel $\mathrm{X}_{1}$ yaitu CAR menghasilkan tingkat signifikan sebesar 0,583 artinya lebih besar dari 0,05 maka dapat disimpulkan bahwa CAR tidak berpengaruh terhadap ROA. Pada Variabel $\mathrm{X}_{2}$ yaitu mengenai FDR menghasilkan tingkat signifikan sebesar 0,003 artinya lebih kecil dari tingkat signifikan 0,05. Maka dari itu dapat disimpulkan bahwa FDR berpengaruh terhadap ROA. Pada Variabel $\mathrm{X}_{3}$ yaitu mengenai BOPO menghasilkan tingkat signifikan sebesar 0,000 artinya lebih kecil dari tingkat signifikan 0,05. Maka dari itu dapat disimpulkan bahwa BOPO berpengaruh terhadap ROA.

\section{Uji F}

Uji F memiliki tujuan untuk menguji apakah sebuah model pada penelitian ini yaitu variabel indipenden memiliki pengaruh secara bersamaan terhadap variabel dependen. Berikut adalah hasil dari uji F dalam penelitian ini :

Tabel 4

Hasil Uji F

ANOVA $^{\mathrm{a}}$

\begin{tabular}{|c|c|c|c|c|c|c|}
\hline Model & & Sum of Squares & df & Mean Square & $\mathrm{F}$ & Sig. \\
\hline \multirow{3}{*}{1} & Regression & 106,775 & 3 & 35,592 & 19,644 &, $000^{\mathrm{b}}$ \\
\hline & Residual & 54,355 & 30 & 1,812 & & \\
\hline & Total & 161,130 & 33 & & & \\
\hline
\end{tabular}

a. Dependent Variable: ROA

b. Predictors: (Constant), BOPO, FDR, CAR

Sumber: Data diolah peneliti,2021

Berdasarkan tabel 4 mengenai uji F yang bertujuan untuk mengetahui secara simultan mengenai pengaruh CAR,FDR dan BOPO terhadap ROA. Pada uji F diats menghasilkan Fhitung sebesar 19,644 dengan $F_{\text {tabel }}$ sebesar 3,305. Dengan demikian $F_{\text {hitung }}>F_{\text {tabel }}$ dan signifikan sebesar 0,000 lebih kecil dari 0,05. Maka dapat disimpulkan bahwa CAR,FDR dan BOPO berpengaruh terhadap ROA.

\section{$\mathrm{H}_{1}$ : Pengaruh CAR terhadap ROA}

Nilai signifikan CAR pada uji $t$ sebesar 0,587 artinya lebih besar dari 0,05 sehingga menyimpulkan bahwa CAR tidak memiliki pengaruh terhadap ROA. Hal ini menunjukkan bahwa ketika CAR mengalami kenaikan tidak berdampak terhadap naiknya ROA. Hal ini sejalan dengan (Munir 2018) yang menyatakan bahwa CAR tidak memiliki pengaruh terhadap ROA

\section{$\mathrm{H}_{2}$ : Pengaruh FDR terhadap ROA}


Nilai signifikan CAR pada uji $\mathrm{t}$ sebesar 0,003 artinya lebih kecil dari 0,05 sehingga menyimpulkan bahwa FDR memiliki pengaruh terhadap ROA. Hal ini disebabkan karena semakin besar besarnya nilai FDR pada Bank Umum Syariah akan menyebabkan naiknya ROA. Hal ini sejalan dengan penelitian yang telah dilakukan oleh (Munir 2018) yang menyatakan bahwa FDR memiliki pengaruh terhadap ROA.

\section{$\mathrm{H}_{3}$ : Pengaruh BOPO terhadap ROA}

Nilai signifikan BOPO pada uji t sebesar 0,000 artinya lebih kecil dari 0,05 sehingga menyimpulkan bahwa BOPO memiliki pengaruh terhadap ROA. Sehingga dapat disimpulkan bahwa semakin besar BOPO menunjukkan bahwa kemampuan bank dalam menekan biaya operasional dan meningkatkan pendapatan operasional akan berakibat terhadap turunnya laba yang akan dihasilkan bank sehingga akan berakibat pada turunnya ROA. Hal ini sejalan dengan penelitian (Suwandi and Oetomo 2017) menyatakan bahwa BOPO berpengaruh negative terhadap ROA

\section{$\mathrm{H}_{4}$ : Pengaruh CAR, FDR dan BOPO terhadap ROA}

Pada uji $\mathrm{F}$ atau pengujian secara bersama-sama menunjukkan hasil signifikan sebesar 0,00 artinya lebih kecil dari 0,05 sehingga menyimpulkan bahwa CAR, FDR dan BOPO berpengaruh terhadap ROA. Hal ini disebabkan karena pada uji t bahwa variabel FDR dan BOPO memiliki pengaruh terhadap ROA. Sehingga dapat disimpulkan bahwa meningkatnya FDR dan BOPO dapat berdampat terhadap ROA.

\section{KESIMPULAN}

Berdasarkan hasil penelitian menyatakan bahwa secara parsial CAR tidak berpengaruh terhadap ROA serta FDR berpengaruh terhadap ROA dan BOPO berpengaruh negative dan signifikan terhadap ROA. Secara bersama-sama atau simultan menyatakan bahwa CAR, FDR dan BOPO berpengaruh signifikan terhadap ROA. Penelitian mengenai faktor-faktor yang mempengaruhi kinerja keuangan dengan mempertimbangkan saran agar penelitian dapat berkualitas serta dapat memberikan hasil yang lebih baik maka disarankan agar penelitian yang akan dilakukan selanjutnya diharapkan dapat menambah variabel-variabel lain serta dapat menambahkan periode penelitian.

\section{DAFTAR PUSTAKA}

Ali, Muhammad, and R. Roosaleh Laksono. 2017. "Pengaruh Net Interest Margin (NIM), Biaya Operasional Terhadap Pendapatan Operasional (BOPO), Loan To Deposit Ratio (LDR) Dan Non Performing Loan (NPL) Terhadap Return on Assets (ROA)." Jurnal Riset Akuntansi dan Keuangan 5(2): 1-16.

Dendawijaya, Lukman. 2005. “Manajemen Perbankan."

- - - 2009. "Manajemen Perbankan, Edisi Ketiga." Bogor: PT. Ghalia Indonesia.

Fahmi, Irham. 2014. "Analisis Laporan Keuangan Bandung: Alfabeta."

- - - 2015. "Manajemen Perbankan Konvensional Dan Syariah." Jakarta: Mitra Wacana Media.

Hamdani, Hamdani, Nining Wahyuni, Ali Amin, and Sulfitra Sulfitra. 2018. "Analisis Faktor-Faktor Yang Mempengaruhi Kinerja Keuangan Bank Umum Syariah Yang Terdaftar Di Bursa Efek Indonesia (BEI) (Periode 2014-2016)." Jurnal Ekonomi dan Manajemen Teknologi (EMT) 2(2): 55109.

Hanafi, Mamduh M, and Abdul Halim. 2012. "Analisis Laporan Keuangan, Edisi Keempat." 
Yogyakarta: UPP STIM YKPN.

Marisya, Fitria. 2019. “Analisis Pengaruh Struktur Modal (CAR) Dandana Pihak Ketiga (FDR) Terhadap Profitabilitas (ROA) Dengan Kredit Bermasalah (NPF) Sebagai Varibel Intervening Pada Perbankan Umum Syariah Di Indonesia." JAZ:Jurnal Akuntansi Unihaz 2(2): 1.

Mujtahidah, Imama, and Nur Laily. 2016. "Pengaruh Rasio Likuiditas, Rasio Aktivitas Dan Rasio Solvabilitas Terhadap Profitabilitas." Jurnal Ilmu dan Riset Manajemen 5(11): 1-18.

Munir, Misbahul. 2018. "Analisis Pengaruh CAR, NPF, FDR Dan Inflasi Terhadap Profitabilitas Perbankan Syariah Di Indonesia." Ihtifaz: Journal of Islamic Economics, Finance, and Banking 1(1): 89.

Prastowo, Dwi. 2015. Analisis Laporan Keuangan. Yogyakarta: Unit Penerbit dan Percetakan Sekolah Tinggi Ilmu Manajemen YKPN.

Simatupang, Apriani;, and Denis Franzlay. 2016. "Capital Adequacy Ratio(CAR), Non Performing Financing (NPF), Efisiensi Operasional (BOPO) Dan Financing to Deposit Ratio (FDR) Terhadap Profitabilitas Bank Umum Syariah Di Indonesia." Administrasi Kantor 4(2): 466-85.

Sudarsono, Heri. 2017. "Analisis Pengaruh Kinerja Keuangan Terhadap Profitabilitas Bank Syariah Di Indonesia." jurnal ekonomi islam 8: 175-203.

Sudarsono, Heri, and Indri Supriani. 2018. "Analisis Pengaruh Variabel Mikro Dan Makro Terhadap Npf Perbankan Syariah Di Indonesia." Equilibrium: Jurnal Ekonomi Syariah 6(1): 1.

Sugiyono, P D. 2017. "Metode Penelitian Bisnis: Pendekatan Kuantitatif, Kualitatif, Kombinasi, Dan R\&D." Penerbit CV. Alfabeta: Bandung.

Suwandi, Jordi, and Hening Widi Oetomo. 2017. "Pengaruh CAR, NPL, BOPO, Dan LDR Terhadap ROA Pada BUSN DEVISA." Jurnal Ilmu dan Riset Manajemen 6 No. 7: 1-21.

Syakhrun, Muhammad, Asbi Amin, and Anwar. 2019. "Pengaruh Car,Bopo, Npf Dan Fdr Terhadap Profitabilitas Pada Bank Umum Syariah Di Indonesia." Bongaya Journal For Research In Managemen 2(2615-8868): 1-10.

Wahyuni, Mirasanti. 2016. "Pengaruh Volume Pembiayaan Bagi Hasil Dan Pembiayaan Murabahah Terhadap Kinerja Keuangan Bank Umum Syariah Dengan NPF Sebagai Variabel Moderasi." Jurnal EBBANK 7(1): 1-10. http://ebbank/article/viewFile/84/85.

Widantika, Anggi, and others. 2017. "Pengaruh Dana Pihak Ketiga Dan Likuiditas Terhadap Profitabilitas Perbankan Bumn Di Indonesia Periode 2008-2015." 